\title{
Analysis of Droughts in the Central Region of South Africa and Their Association with SST Anomalies
}

\author{
Desalegn C. Edossa, Yali E. Woyessa, and Worku A. Welderufael \\ Department of Civil Engineering, Central University of Technology, Free State (CUT), 20 President Brand Street, \\ Private Bag Box X20539, Bloemfontein 9300, South Africa \\ Correspondence should be addressed to Desalegn C. Edossa; dedossa@cut.ac.za
}

Received 18 June 2014; Revised 1 November 2014; Accepted 3 December 2014; Published 25 December 2014

Academic Editor: Hui Wang

Copyright (C) 2014 Desalegn C. Edossa et al. This is an open access article distributed under the Creative Commons Attribution License, which permits unrestricted use, distribution, and reproduction in any medium, provided the original work is properly cited.

\begin{abstract}
The objective of this study was to characterise meteorological droughts in the Central Region of South Africa using Standardised Precipitation Evapotranspiration Index (SPEI) and to examine if there is a relationship between drought and El Niño events. The SPEI was used to quantify the precipitation deficit over time and space across the catchment for the time-scales that are important for planning and management of water resources. Based on 12-month time-scale, the total number of drought events identified in the area using SPEI ranged between 13 and 20 during the period of analysis (1952-1999). Considering the effects of event magnitude and duration as severity parameters, the most severe drought event was identified during 1973 followed by 1995 based on 12 month time-scale. Moreover, it was also found that the number of moderate, severe, and extreme drought events identified by SPEI follows increasing trend with decade during the period of analysis. Results of Spearman's rank correlation test revealed that the trends exhibited by mild (SPEI-3 and SPEI-6), moderate (SPEI-12), severe (SPEI-12), and extreme (SPEI-3) drought categories are statistically significant at $5 \%$ significance level. The study also revealed that drought events in the central region of South Africa are preceded by El Niño events in the tropical Pacific (Nino 3.4) with an average lag time of 8 months between the onsets of the two events. It was found that hydrological drought events in the study area lag behind meteorological drought events with an average lag time of 7.4 months. Findings of this study can be used to forecast drought events in the area for the proper planning and management of water resources.
\end{abstract}

\section{Introduction}

It is well established that precipitation characteristics have changed, and they will continue to change towards more intense and intermittent spells [1]. This translates into more frequent and more severe water-related extreme events. For example, Rouault and Richard [2] reported an increase in the spatial extent of drought in southern Africa since the 1970s due to stronger relationship between El Niño Southern Oscillation (ENSO) and the southern African rainfall. Janowiak [3] reported that positive rainfall departures in equatorial East Africa and negative departures in South Africa followed ENSO events. Nicholson and Kim [4] made a comprehensive assessment of the rainfall response to ENSO episodes over Africa and reported that the strongest signals have appeared in southern, eastern, and far northern Africa and the weakest in the Sahel. Nicholson and Entekhabi [5] studied the relationship between rainfall in equatorial and southern Africa and the SST along the southwestern coast of Africa. Nicholson [6] and Nicholson and Kim [4] concluded that the ENSO episodes that influenced rainfall over Africa were those that manifested as SST fluctuations in the low-latitude Atlantic and western Indian oceans. In recent years, Reason and Rouault [7] reported an ENSOlike decadal variability in South African rainfall. Rouault et al. [8] examined the relationship between southeast tropical Atlantic warm events and southern African rainfall. Reason et al. [9] reported results of interannual variability in rainfall over the Limpopo Province of South Africa.

Drought is a normal part of climate phenomenon in almost every country, but it has serious economic, environmental, and social impacts which affect more people than any other natural hazard, particularly the poor who are more vulnerable. This is a cause for concern as the world is entering a period of unprecedented climate change, which is predicted to result in higher average temperatures, changes 
in precipitation patterns, and more frequent extreme weather events over extensive land areas $[10,11]$. Therefore, countries must address the underlying causes of drought vulnerability and improve monitoring and early warning systems.

In South Africa's arid and semiarid areas, droughts are a frequent occurrence [12]. While these may be short-term and followed by recovery during subsequent years of higher rainfall [13], in some cases droughts can trigger substantial and irreversible ecological and socioeconomic changes. Model predictions indicate that reductions in mean annual rainfall, increased interannual variation, and more frequent droughts in South Africa can lead to disproportionately large impacts on livestock production [14]. Seymour and Desmet [15] suggest that long-term drought research is essential in the country and underlined the importance of a suite of coordinated long-term field observations, experiments, and models to inform agricultural policy and conservation planning.

All drought types, namely, meteorological, agricultural, hydrological, and socioeconomic droughts, originate with a deficiency in precipitation. Meteorological drought measures precipitation departure from normal over some period of time and is one of the primary causes of droughts. On the other hand, agricultural drought is exhibited by soil moisture deficit during the growing period and is mostly related to rain-fed agriculture. The longer and the more spatially extensive this deficiency, the more likely the occurrence of other types of droughts, such as the occurrence of hydrological drought that is a deficiency in the bulk water supply, which may include water levels in streams, lakes, reservoirs, and aquifers [16]. Socioeconomic drought associates droughts with supply of and demand for one of the economic goods.

Although it is not possible to avoid drought, its impacts can be managed through preparedness planning. The success of drought preparedness and management depends, among others, on how well the droughts are defined and drought characteristics are quantified temporally as well as spatially. Various drought indices have been developed to characterise drought spatially and temporally based on its magnitude, duration, and intensity. Drought indices commonly applied around the world are summarized by Smakhtin and Hughes [17]. Du Pisani et al. [18] reported review of various drought assessment techniques that have been developed in South Africa prior to 1998. Drought indices derived from meteorological data, primarily precipitation and temperature, could be used to monitor not only meteorological droughts but also agricultural and hydrological droughts which are important for developing a drought watch system for an area. Recent studies have used meteorological drought indices as indicators of hydrological and water resources variables, like soil moisture, surface runoff, and reservoir and groundwater storages [19-23].

The purpose of this paper is to characterise drought events in the Central Region of South Africa using Standardised Precipitation Evapotranspiration Index (SPEI) and to examine the association between drought and El Niño events. The SPEI was formulated based on two meteorological variables, precipitation and temperature, and can account for the possible effects of temperature variability and temperature extremes in the context of global warming.

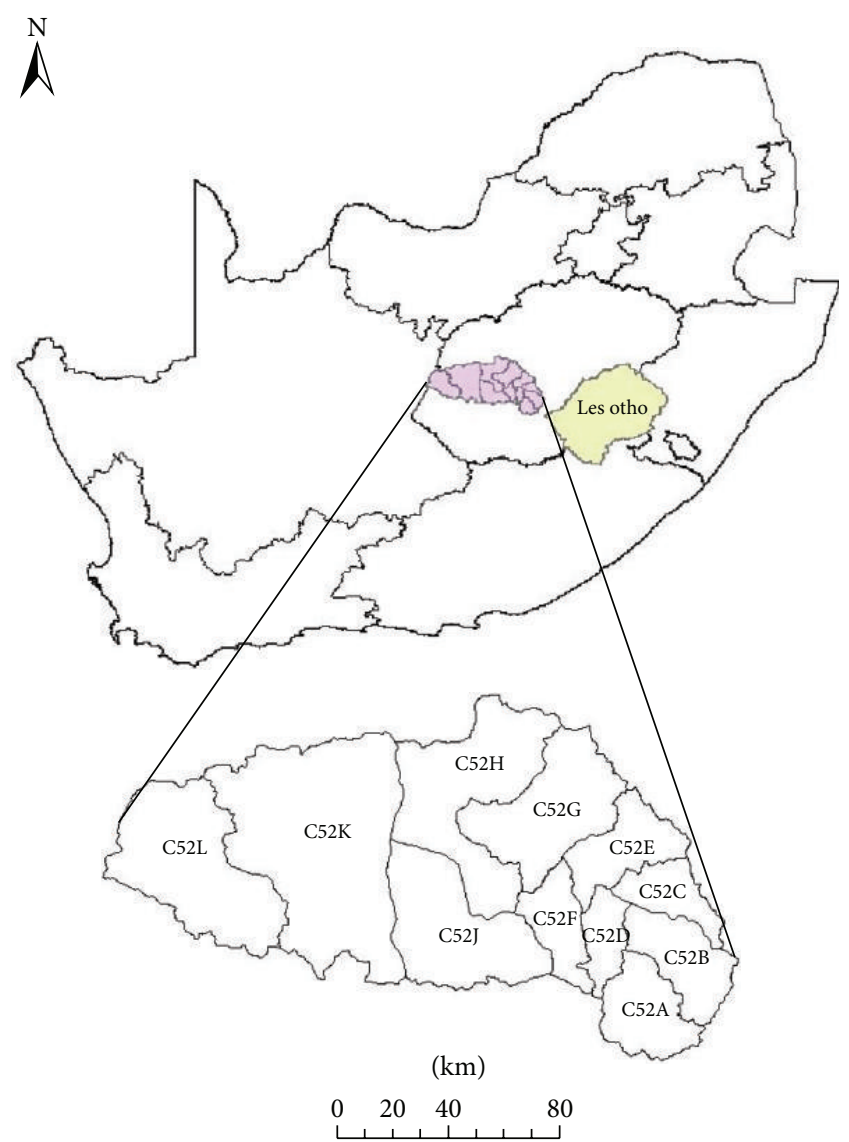

FIGURE 1: Location of the study area.

\section{Materials and Methods}

2.1. Location of the Study Area. The study was carried out in the Modder River basin, C52 tertiary catchment. The basin has a total area of $17,380 \mathrm{~km}^{2}$ and is divided into three subbasins, namely, the Upper Modder, the Middle Modder, and the Lower Modder. It is located within the Upper Orange Water Management Area to the east of the city of Bloemfontein and consists of 11 quaternary catchments (Figure 1). The Upper Modder which consists of the quaternary catchment C52A comprises approximately $5 \%$ of the total runoff contributing area. The Middle Modder consists of the second largest portion of the basin area. It covers about $45 \%$ of the total area and includes quaternary catchments C52B, C52C, C52D, C52E, C52F, C52G, and C52H. The remaining 50\% of the total area belongs to the lower Modder basin and is divided into three quaternary catchments, namely, C52J, C52K, and C52L [24].

The dominant soil types of the catchment are sandy clay loam and sandy clay [25]. The irrigated agriculture in the basin mainly uses water supplied by pumping from rivers and weirs. However, many of the rural farmers rely on rain-fed agriculture for crop production. The basin is experiencing intermittent droughts causing water shortages for agriculture, livestock, and domestic purposes. 
Daily precipitation and temperature data of the 11 quaternary catchments were obtained from QCD_DAT.EXE, a selfextracting compressed data file containing 50 years (19501999) of daily hydroclimatic data pertaining to each of the 1946 quaternary catchments of South Africa [26]. In this analysis, the quaternary catchments' databases have been used for the analysis of droughts in the tertiary catchment using SPEI. Historic El Niño/La Niña events since 1950 were obtained from the Climate Prediction Center of the National Oceanic and Atmospheric Administration (NOAA) website. Monthly stream flow data of Modder River at Bultfontein (outlet of C52G quaternary catchment) during 1971-1999 were obtained from website of the Department of Water Affairs, South Africa, to determine if there is any link between the meteorological and hydrological droughts in the study catchment.

2.2. Identification and Characterization of Droughts. The SPEI uses the monthly difference between precipitation and potential evapotranspiration (PET). The monthly PET is calculated based on Thornthwaite's formula [27]. This represents a simple climatic water balance expressed in terms of SPEI which is calculated at different time-scales (e.g., 1-, 3-, 6-, 12-, 24-, and 48-month) which allows evaluation of the effects of a precipitation deficit on different water resources components (groundwater, reservoir storage, soil moisture, and streamflow). Moving total time series is constructed from the data generated by deducting PET from precipitation data and then used for the SPEI computation. The first step in the calculation of the SPEI is to determine a probability density function that describes the long-term series of the data. Once this distribution is determined, the cumulative probability is computed and the inverse normal (Gaussian) function is then applied to the probability.

The values of SPEI can be categorised according to the classes indicated in Table 1 . SPEI values are positive or negative for greater or less than the normal value, respectively. The departure from the normal is a probability indication of the severity of the wetness or drought that can be used for risk assessment.

2.3. Temporal Analysis of Droughts. The time series of the SPEI are used to characterise droughts based on duration, magnitude, and intensity of the events. A drought event occurs anytime the SPEI values are continuously negative and ends when the values become positive. Each drought event, therefore, has a duration defined by its beginning and end. The positive sum of the SPEI values for all the months within a drought event is termed as drought magnitude. Therefore, intensity of a drought event is defined as the ratio of event magnitude to its duration.

\section{Results and Discussions}

3.1. Identification of Drought Events. During the period of analysis, the total number of drought episodes detected in the study area by SPEI based on multiple time-scales is presented in Table 2. Based on a 24-month time-scale, the total number of drought episodes detected in the study area
TABLE 1: Classification of SPEI values.

\begin{tabular}{lc}
\hline SPEI class & Class description \\
\hline SPEI $\leq-2$ & Extremely dry \\
$-2<\mathrm{SPEI} \leq-1.5$ & Severely dry \\
$-1.5<\mathrm{SPEI} \leq-1$ & Moderately dry \\
$-1<\mathrm{SPEI} \leq 0$ & Mild drought \\
$0<\mathrm{SPEI} \leq 1$ & Near normal wet \\
$1<\mathrm{SPEI} \leq 1.5$ & Moderately wet \\
$1.5<\mathrm{SPEI} \leq 2$ & Very wet \\
$\mathrm{SPEI}>2$ & Extremely wet \\
\hline
\end{tabular}

Source: [28].

ranged between 10 (C52G and $\mathrm{C} 52 \mathrm{H}$ ) and 15 (C52E and C52L). Similarly, on the basis of a 12-month time-scale, the number of drought episodes detected in the area ranged from 13 (C52G and C52H) to 20 (C52B and C52D). It is interesting to note that the widespread and sustained drought events that have periodically afflicted southern Africa during the 2 nd half of the 20th century, namely, 1964, 1968, 1970, 1982, 1983, 1984, and 1992/93 [29], have been captured by SPEI.

3.2. Relative Frequency of Drought Events. Table 3 presents relative frequencies of droughts of various categories identified by SPEI at C52A quaternary catchment with respect to the total number of drought events recorded in the area during the analysis period. The numbers shown in the table are obtained by calculating the ratio of the number of drought events corresponding to each time-scale and drought category to the total number of drought events recorded in the same time-scale and category. The results show that for a given time-scale mild droughts occur most frequently and extreme droughts occur least frequently in the area, as is expected. For all time-scales, the similar distribution of drought events over different drought categories is due to the transformation of the derived SPEI values to follow a normal distribution.

3.3. Temporal Analysis of Drought Events. The 3-month SPEI values reflect short- and medium-term moisture conditions and provide a seasonal estimation of precipitation deficiency. The 6-month values indicate medium-term trends in precipitation deficiency and can be very effective showing the precipitation over distinct seasons. Information from a 6-month SPEI value may also begin to be associated with anomalous streamflow and reservoir conditions. However, the values at 12-month time-scale reflect long-term precipitation patterns. Plots of time series of SPEI (at three time-scales) in the C52A quaternary catchment for the summer months (DecemberJanuary) are presented in Figures 2(a)-2(c).

Based on the 12-month time scale, two extreme drought events were recorded in the area in February 1993 and 1995 and one extreme drought event in January 1993. However, no extreme drought event was recorded in December based on the 12-month time-scale. Similarly, based on 6-month timescale, one extreme drought event was recorded in the area in January 1973 whereas no extreme drought was recorded in the other two summer months. It can be noted that the 


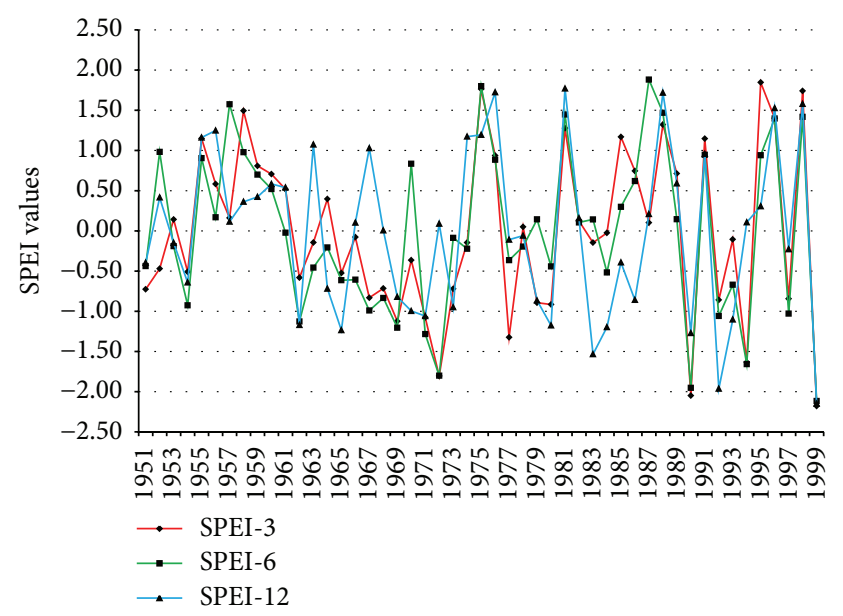

(a) December

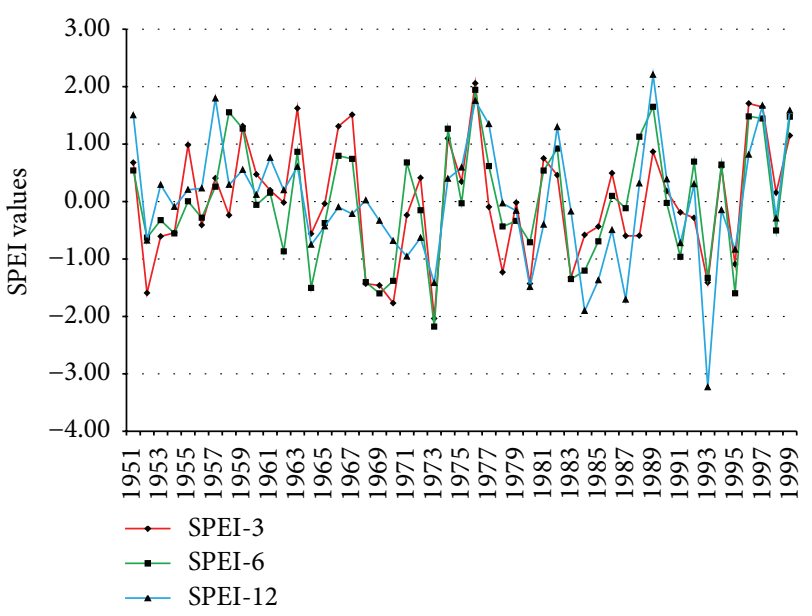

(b) January

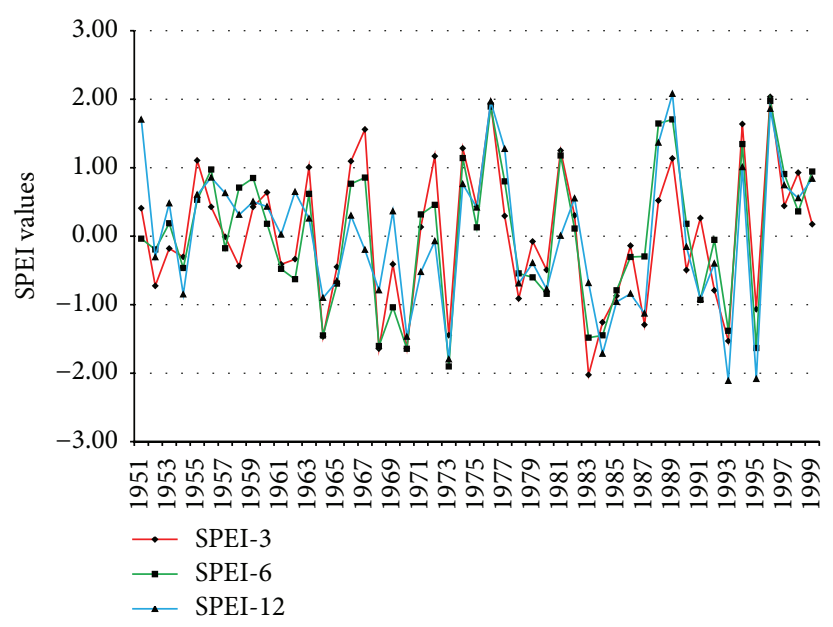

(c) February

Figure 2: Time series of SPEI values computed for C52A quaternary catchment in the three summer months (a) December, (b) January, and (c) February.

TABLE 2: Number of drought events identified in the study area using SPEI at multiple time-scales.

\begin{tabular}{lccccccccccc}
\hline & C52A & C52B & C52C & C52D & C52E & C52F & C52G & C52H & C52J & C52K & C52L \\
\hline 3-month & 36 & 42 & 38 & 39 & 40 & 33 & 40 & 40 & 39 & 40 & 42 \\
6-month & 29 & 32 & 27 & 29 & 28 & 27 & 29 & 28 & 25 & 28 & 30 \\
12-month & 17 & 20 & 19 & 20 & 17 & 18 & 13 & 13 & 18 & 16 & 19 \\
24-month & 12 & 14 & 13 & 14 & 15 & 13 & 10 & 10 & 13 & 13 & 15 \\
\hline
\end{tabular}

TABLE 3: Relative frequency of drought events at C52A quaternary catchment.

\begin{tabular}{lccc}
\hline Drought category & SPEI-3 & SPEI-6 & SPEI-12 \\
\hline Extreme drought & 2.55 & 2.88 & 2.68 \\
Severe drought & 11.90 & 12.68 & 10.71 \\
Moderate drought & 20.40 & 19.31 & 24.70 \\
Mild drought & 65.16 & 65.13 & 61.90 \\
\hline
\end{tabular}

quaternary catchment has been under persistent drought event during the three summer months in the years 19901993 regardless of the event category.
Table 4 presents characteristics of individual drought events identified in C52A quaternary catchment by SPEI based on 12-month time-scale. Each drought event was characterised based on its duration, magnitude (sum of all negative values of SPEI during the event), and intensity (the ratio of event magnitude to its duration) in order to understand the severity of individual drought events. Based on drought intensity, it can be noted that the most severe drought event was recorded in the year 1973 (between January and December) followed by the year 1995 (between January and November).

Figure 3 shows decadal variations of drought events in the quaternary catchment. Decades 1, 2, 3, 4, and 5 represent the 
TABLE 4: Characterization of drought events based on SPEI-12 in C52A.

\begin{tabular}{lcccc}
\hline Onset & End & Duration (months) & Magnitude & Intensity \\
\hline Jan-52 & Jun-52 & 6 & -2.37 & -0.40 \\
Aug-53 & Dec-54 & 17 & -5.56 & -0.33 \\
Mar-57 & Aug-57 & 6 & -4.32 & -0.72 \\
Sep-58 & Nov-58 & 3 & -0.98 & -0.33 \\
Mar-62 & Dec-62 & 10 & -5.84 & -0.58 \\
Jan-64 & Jan-66 & 25 & -22.08 & -0.88 \\
Jul-66 & Feb-67 & 8 & -1.61 & -0.20 \\
Feb-68 & Jan-69 & 12 & -2.86 & -0.24 \\
Apr-69 & Apr-71 & 25 & -26.91 & -1.08 \\
Aug-71 & Feb-72 & 7 & -4.36 & -0.62 \\
Jan-73 & Dec-73 & 12 & -20.43 & -1.70 \\
Dec-77 & Jan-81 & 38 & -26.98 & -0.71 \\
Jan-83 & Aug-87 & 56 & -59.71 & -1.07 \\
Oct-90 & Sep-91 & 12 & -10.20 & -0.85 \\
Feb-92 & Jan-94 & 24 & -32.04 & -1.33 \\
Jan-95 & Nov-95 & 11 & -15.80 & -1.44 \\
Mar-99 & Dec-99 & 10 & -5.29 & -0.53 \\
\hline
\end{tabular}

years 1951-1960, 1961-1970, 1971-1980, 1981-1990, and 19911999 , respectively. Based on the plots of decadal variations of drought events, it can be noted that outputs of this analysis based on all time-scales (3-, 6-, and 12-month) show an increasing trend of moderate to extreme drought events in the quaternary catchment. However, the changes in mild drought events based on all the three time-scales show high decadal fluctuations with no defined trend.

Spearman's rank correlation method (with $t_{\text {critical }}=3.18$ and $\mathrm{df}=3$ ) was used to test whether the trends shown in the plots are statistically significant at $5 \%$ significance level. The observed/calculated values of $t$ (obs. $t$ ) for each drought category are shown on the plots. Results of the analysis show that the trends exhibited by two extreme and mild, one mild, and, two severe and moderate drought categories under SPEI-3, SPEI-6, and SPEI-12, respectively, are statistically significant at $5 \%$ significance level. It can be noted that mild droughts in all the three time-scales show decreasing trends. The infinitely large value of observed $t$ corresponding to severe drought under SPEI-12 was due to the fact that the calculation of Spearman's rank correlation coefficient $\left(R_{\mathrm{sp}}\right)$ returned the maximum value (unity) signifying a perfect Spearman correlation between the decade and the number of drought events.

3.4. Link between Drought and El Niño Events. Figure 4 shows plots of SST anomaly (at Nino 3.4) and SPEI-12 and SPEI-24 for C52A quaternary catchment. Although the relationship between SST anomalies and SPEI outputs is not strong, there is a clear indication that most of the drought events identified by SPEI (Table 4) follow El Niño events. It was found that 7 out of the total of 17 drought events identified in the area (41\%) succeeded El Niño events. This indicates that not all drought events in the area, even in El Niño years, are due to El Niño. It is interesting to note that most of the popular drought events in South Africa that have also been properly captured
TABLE 5: El Niño and drought events based on SEPI-12.

\begin{tabular}{lcccc}
\hline \multicolumn{2}{c}{ El Niño event } & \multicolumn{2}{c}{ Drought event } & \multirow{2}{*}{ Lag time (month) } \\
Onset & End & Onset & End & 8 \\
\hline Jan-53 & Feb-54 & Aug-53 & Dec-54 & 8 \\
Jun-63 & Feb-64 & Jan-64 & Jan-66 & 9 \\
Aug-68 & Jan-70 & Apr-69 & Apr-71 & 9 \\
May-72 & Mar-73 & Jan-73 & Dec-73 & 4 \\
Sep-77 & Feb-78 & Dec-77 & Jan-81 & 9 \\
May-82 & Jun-83 & Jan-83 & Aug-87 & 4 \\
Sep-94 & Mar-95 & Jan-95 & Nov-95 & 7.3 \\
\hline \multicolumn{5}{c}{ Average lag $=$} \\
\hline
\end{tabular}

by SPEI (such as 1953, 1964, 1969, 1973, 1977, 1983, and 1995) occurred following the El Niño events. It can be noted that the 1982-83 El Niño event, which is perhaps the strongest event in recorded history, has caused the worst drought event of 1983 in the region. Table 5 presents pairing of the two events (El Niños and the corresponding drought events).

Attempts have also been made to identify the lag time between the onsets of the two events (El Niño and drought events). Results of analysis of cross-correlation between SST anomaly and SPEI-12 show that drought events in the area lag behind the El Niño event by 8 months. Figure 5 shows plot of cross-correlation values at different lag times. In order to verify this finding, the mean lag time between the two events was also computed manually (Table 5 ) by calculating the differences between the onsets of the two events (El Niño events and the ensuing drought events). In this case, the lag time between the two events was found to be 7.3 months substantiating the result obtained using cross-correlation method.

3.5. Impacts of Drought Events on Water Resources. Figure 6 shows plot of Modder River flow at Bultfontein stream gauging station (1971-1999) at the outlet of C52G quaternary catchment. This analysis was undertaken in order to determine if there is a link between meteorological drought events identified by SPEI and low flows in the Modder River. It is expected that low flows (an indication of hydrological droughts) at Bultfontein gauging station are preceded by meteorological drought events in the upper catchment (C52G). Edossa et al. [20] reported that hydrological drought events lag behind meteorological drought events on average by 7 months. Figure 7 shows plot of SPEI outputs based on 12-month time-scale for the same time slice (1971-1999) for comparison purpose.

It can be noted that most of the meteorological drought events (see events marked as 1-5 on Figures 6 and 7) in the quaternary catchment have been followed by low flow events at Bultfontein stream gauging station. Results of analysis of the lag time between the onsets of meteorological drought events and low flow revealed that the lag time between the hydrological and meteorological drought events is in the range of 4-12 months (with an average lag time of 7.4 months). It is interesting to note that the finding of this study agrees well with results previously reported by Edossa et al. [20]. 


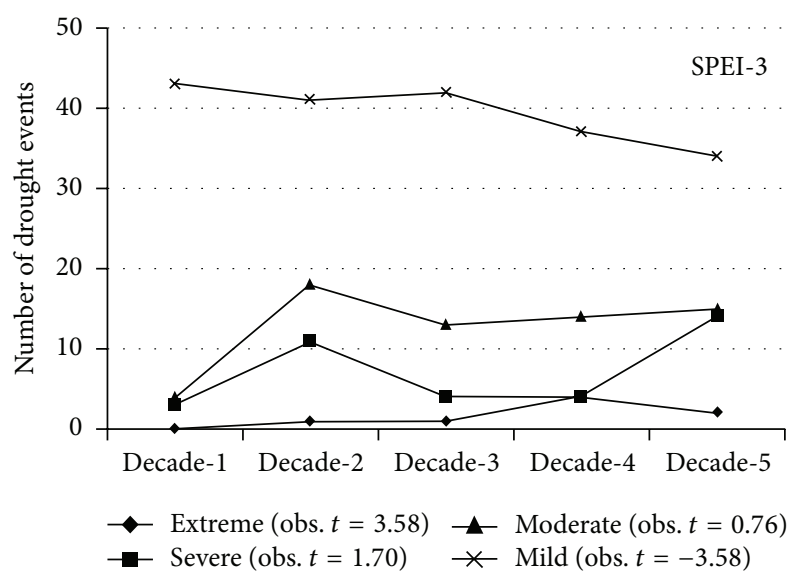

(a)

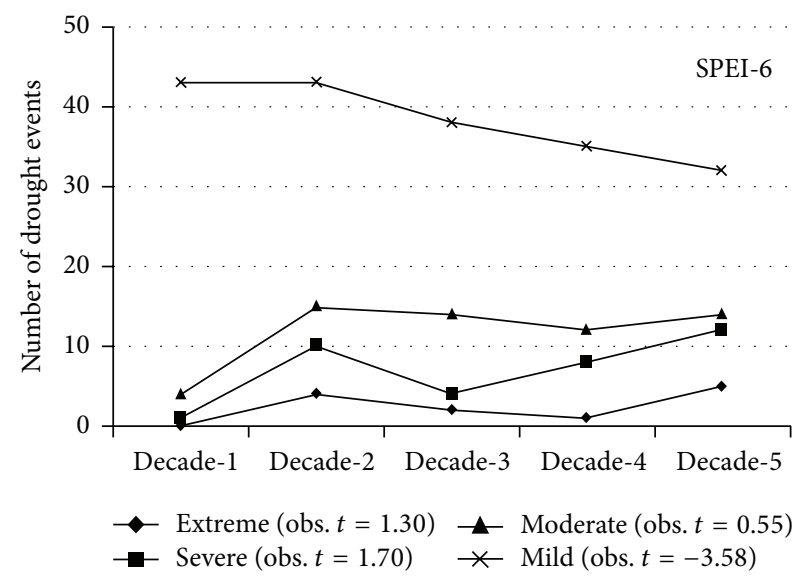

(b)

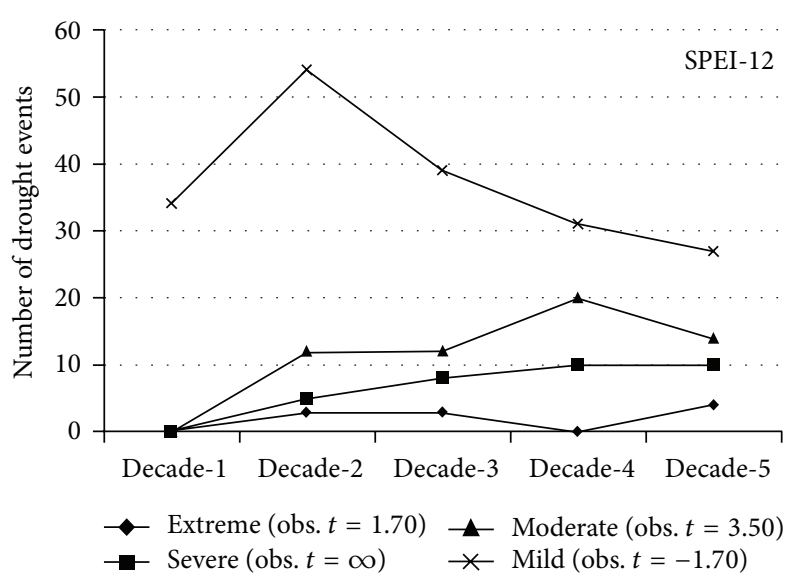

(c)

FIGURE 3: Decadal variation of drought in C52A quaternary catchment based on SPEI.

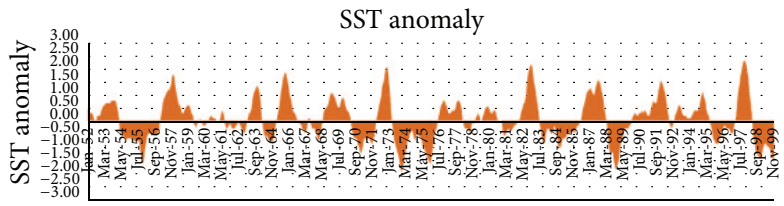

SPEI-12

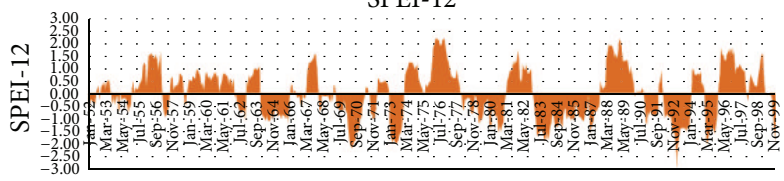

SPEI-24

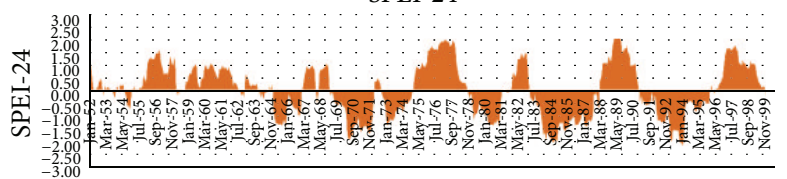

FIGURE 4: Plots of historical SST anomalies (for Nino 3.4) and SPEI-12 and SPEI-24. 


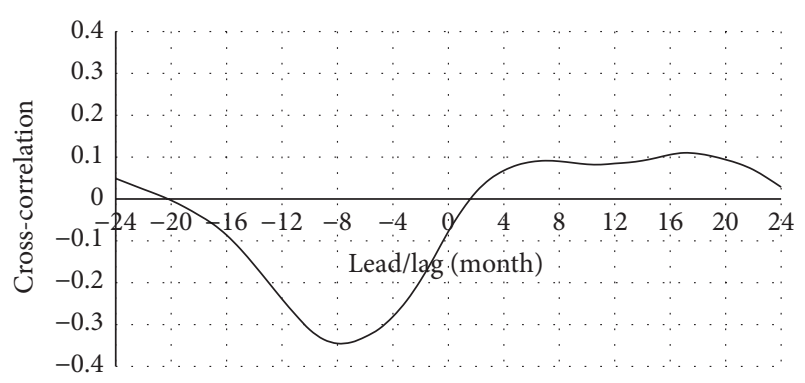

FIGURE 5: Cross-correlation between Nino 3.4 SST anomaly and SPEI-12 with negative lags for SST leading SPEI-12.

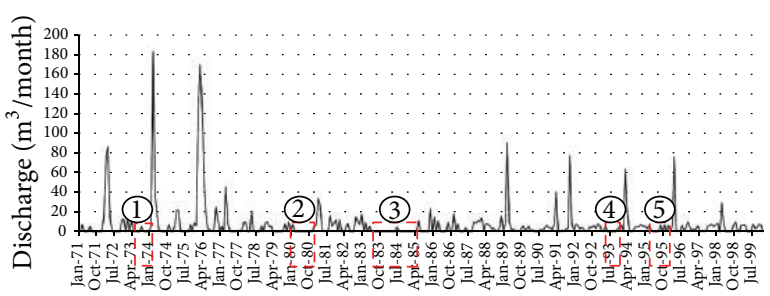

Figure 6: Plot of Modder River flow at Bultfontein gauging station.

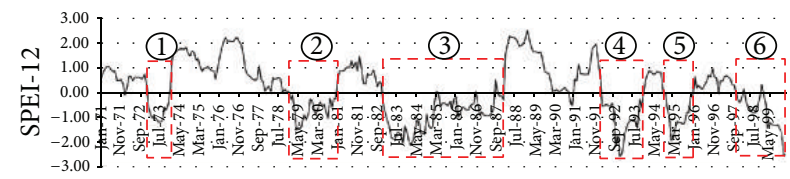

Figure 7: Plot of SPEI-12 in C52G quaternary catchment.

\section{Conclusion}

In this study, drought episodes in the Central Region of South Africa during the period 1952-1999 were analysed using SPEI based on multiple time-scales (3-, 6-, 12-, and 24-month) and links between drought and El Niño events were examined. Based on 24-month time-scale, the total number of drought episodes detected in the study area ranged between 10 (C52G and $\mathrm{C} 52 \mathrm{H})$ and 15 (C52E and C52L). Similarly, on the basis of 12-month time-scale, the number of drought episodes detected in the area ranged from $13(\mathrm{C} 52 \mathrm{G}$ and $\mathrm{C} 52 \mathrm{H})$ to 20 (C52B and C52D). Using drought intensity as severity parameter, the severest drought events were identified in 1973 followed by 1995 based on 12-month time-scale. Analysis of decadal variation of drought events revealed that extreme, severe, and moderate drought events showed increasing trends during the period of analysis. The trends exhibited by mild (SPEI-3 and SPEI-6), moderate (SPEI-12), severe (SPEI-12), and extreme (SPEI-3) drought categories are statistically significant at 5\% significance level. Frequency analysis of drought events identified by SPEI index shows that $\mathrm{C} 52 \mathrm{~K}$ and $\mathrm{C} 52 \mathrm{~B}$ were the two quaternary catchments in the basin most frequently hit by severe and extreme drought events, respectively, based on 12-month time-scale.

The study also examined if there is any link between drought events identified in the area and the historical El Niño events recorded in the central Pacific Ocean. It was found that the drought events in the Central Region of South Africa lag behind the El Niño events by a lag time of 8 months. Moreover, the study revealed that hydrological drought events (in terms of low flows at Bultfontein stream gauging station) lag behind the meteorological drought events in the upstream catchment area (C52G) on average by 7.4 months. These lag times can be used for the development of drought early warning system for the region to reduce impacts of droughts through the proper planning and management of water resources.

\section{Conflict of Interests}

The authors declare that there is no conflict of interests regarding the publication of this paper.

\section{Acknowledgment}

The authors would like to acknowledge the financial support received from the Water Research Commission of South Africa.

\section{References}

[1] S. P. Simonovic, Managing Water Resources: Methods and Tools for a Systems Approach, UNESCO, Paris, France; Earthscan James \& James, London, UK, 2009.

[2] M. Rouault and Y. Richard, "Intensity and spatial extent of droughts in southern Africa," Geophysical Research Letters, vol. 32, no. 15, Article ID L15702, 2005.

[3] J. Janowiak, "An investigation of interannual rainfall variability in Africa," Journal of Climate, vol. 1, no. 3, pp. 240-255, 1988.

[4] S. E. Nicholson and J. Kim, "The relationship of the El Niño/ Southern Oscillation to African rainfall," International Journal of Climatology, vol. 17, pp. 117-135, 1997.

[5] S. E. Nicholson and D. Entekhabi, "Rainfall variability in equatorial and southern Africa: relationships with sea surface temperatures along the southwestern coast of Africa," Journal of Climate \& Applied Meteorology, vol. 26, no. 5, pp. 561-578, 1987.

[6] S. E. Nicholson, "An analysis of the ENSO signal in the tropical Atlantic and western Indian Oceans," International Journal of Climatology, vol. 17, no. 4, pp. 345-375, 1997.

[7] C. J. C. Reason and M. Rouault, "ENSO-like decadal variability and South African rainfall," Geophysical Research Letters, vol. 29, no. 13, pp. 1-4, 2002.

[8] M. Rouault, P. Florenchie, N. Fauchereau, and C. J. C. Reason, "South East tropical Atlantic warm events and Southern African rainfall," Geophysical Research Letters, vol. 30, no. 5, pp. 9-4, 2003.

[9] C. J. C. Reason, S. Hachigonta, and R. F. Phaladi, "Interannual variability in rainy season characteristics over the Limpopo region of southern Africa," International Journal of Climatology, vol. 25, no. 14, pp. 1835-1853, 2005.

[10] F. D. Richardson, B. D. Hahn, and M. T. Hoffman, "Modelling the sustainability and productivity of pastoral systems in the communal areas of Namaqualand," Journal of Arid Environments, vol. 70, no. 4, pp. 701-717, 2007. 
[11] S. Vetter, "Drought, change and resilience in south africa's arid and semi-arid rangelands," South African Journal of Science, vol. 105, no. 1-2, pp. 29-33, 2009.

[12] C. Vogel, "(Mis)management of droughts in South Africa," South African Journal of Science, vol. 90, pp. 4-6, 1994.

[13] J. E. Ellis and D. M. Swift, "Stability of African pastoral ecosystems: alternate paradigms and implications for development," Journal of Range Management, vol. 41, no. 6, pp. 450-459, 1988.

[14] M. Burns, M. Audouin, and A. Weaver, "Advancing sustainability science in South Africa," South African Journal of Science, vol. 102, no. 9-10, pp. 379-384, 2006.

[15] C. Seymour and P. Desmet, "Coping with drought: do science and policy agree?” South African Journal of Science, vol. 105, no. 1-2, pp. 18-19, 2009.

[16] R. R. Heim Jr., "A review of twentieth-century drought indices used in the United States," Bulletin of the American Meteorological Society, vol. 83, no. 8, pp. 1149-1165, 2002.

[17] V. U. Smakhtin and D. A. Hughes, "Review, automated estimation and analyses of drought indices in South Asia," IWMI Working Paper N 83-Drought Series Paper N 1, Colombo, Sri Lanka, 2004.

[18] L. G. Du Pisani, H. J. Fouché, and J. C. Venter, "Assessing rangeland drought in South Africa," Agricultural Systems, vol. 57, no. 3, pp. 367-380, 1998.

[19] S. M. Vicente-Serrano and J. I. López-Moreno, "Hydrological response to different time scales of climatological drought: an evaluation of the Standardized Precipitation Index in a mountainous Mediterranean basin," Hydrology and Earth System Sciences, vol. 9, no. 5, pp. 523-533, 2005.

[20] D. C. Edossa, M. S. Babel, and A. D. Gupta, "Drought analysis in the Awash River Basin, Ethiopia," Water Resources Management, vol. 24, no. 7, pp. 1441-1460, 2010.

[21] F. Fiorillo and F. M. Guadagno, "Karst spring discharges analysis in relation to drought periods, using the SPI," Water Resources Management, vol. 24, no. 9, pp. 1867-1884, 2010.

[22] L. Vasiliades and A. Loukas, "Hydrological response to meteorological drought using the Palmer drought indices in Thessaly, Greece," Desalination, vol. 237, no. 1-3, pp. 3-21, 2009.

[23] J. Lorenzo-Lacruz, S. M. Vicente-Serrano, J. I. López-Moreno, S. Beguería, J. M. García-Ruiz, and J. M. Cuadrat, "The impact of droughts and water management on various hydrological systems in the headwaters of the Tagus River (central Spain)," Journal of Hydrology, vol. 386, no. 1-4, pp. 13-26, 2010.

[24] Y. E. Woyessa, W. A. Welderufael, J. D. M. Kinyua, G. Kundhlande, and O. P. Tsumake, "Land-water linkages: agent-based modelling of land use and its impact on water resources," Water Research Commission Report No. 1753/1/10, 2011.

[25] W. A. Welderufael, Y. E. Woyessa, and D. C. Edossa, "Impact of rainwater harvesting on water resources of the modder river basin, central region of South Africa," Agricultural Water Management, vol. 116, pp. 218-227, 2013.

[26] S. D. Lynch, "The development of a raster database of annual, monthly and daily rainfall for Southern Africa," Report 1156/1/04, Water Research Commission, Pretoria, South Africa, 2004.

[27] C. W. Thornthwaite, "An approach toward a rational classification of climate," Geographical Review, vol. 38, no. 1, pp. 55-94, 1948.

[28] L. Vermes, How to Work out a Drought Mitigation Strategy, ICID Guide, 309/1998, Bonn, Germany, 1998.
[29] L. T. Dube and M. R. Jury, "Structure and precursors of the 1992/93 drought in KwaZulu-Natal, South Africa from NCEP reanalysis data," Water SA, vol. 29, no. 2, pp. 201-207, 2003. 

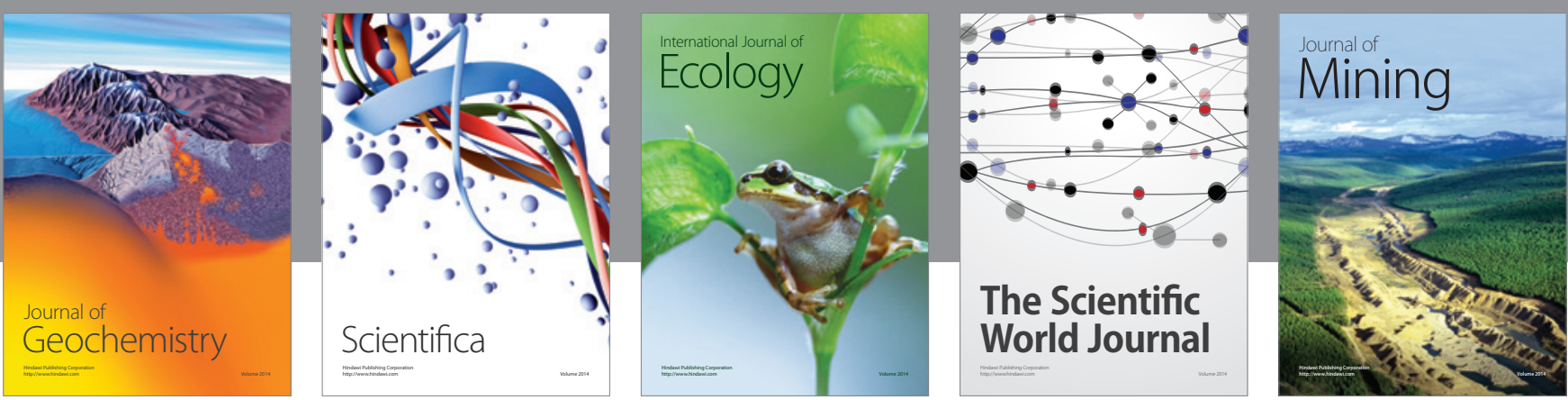

The Scientific World Journal
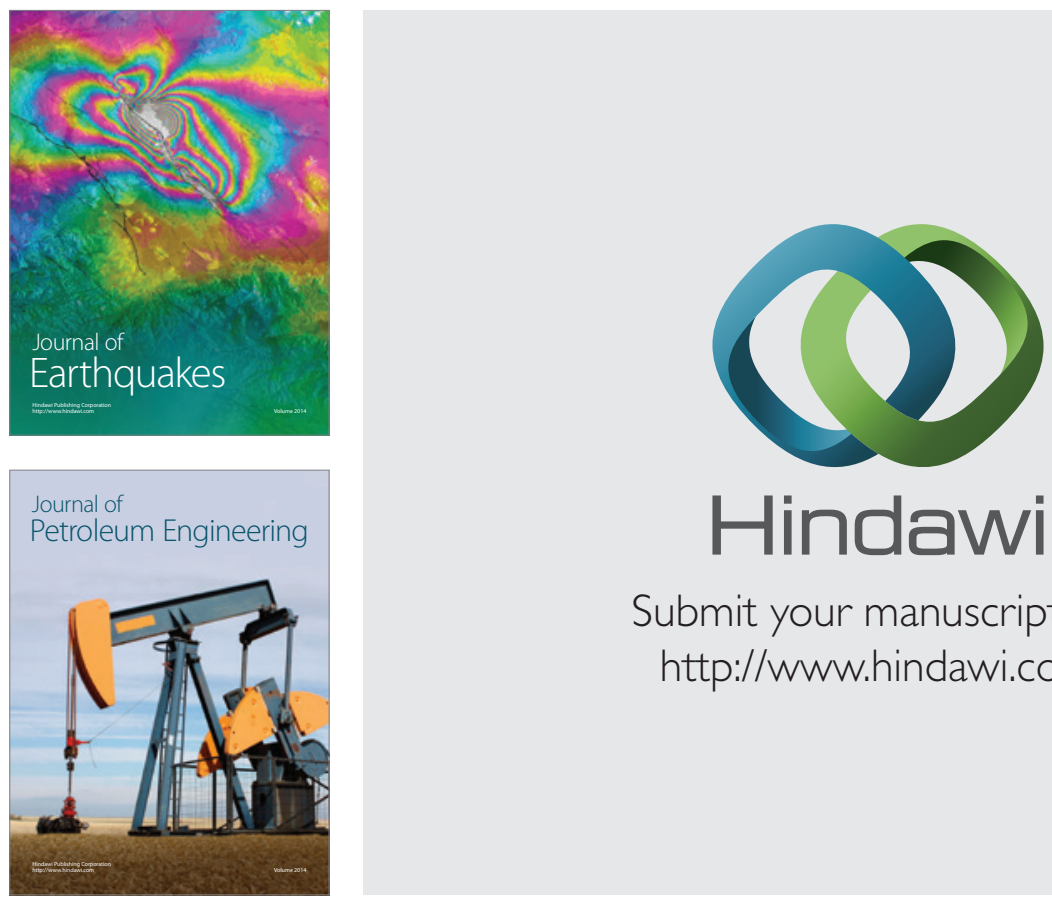

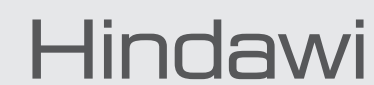

Submit your manuscripts at

http://www.hindawi.com
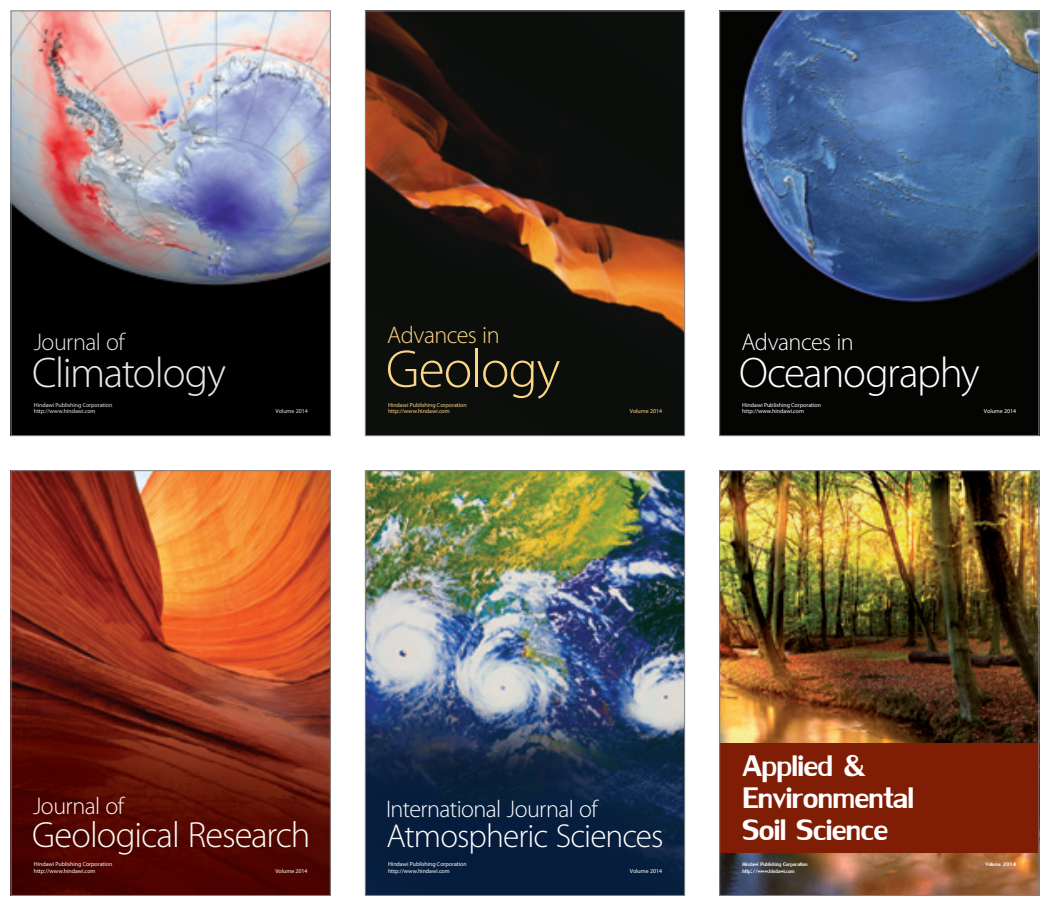
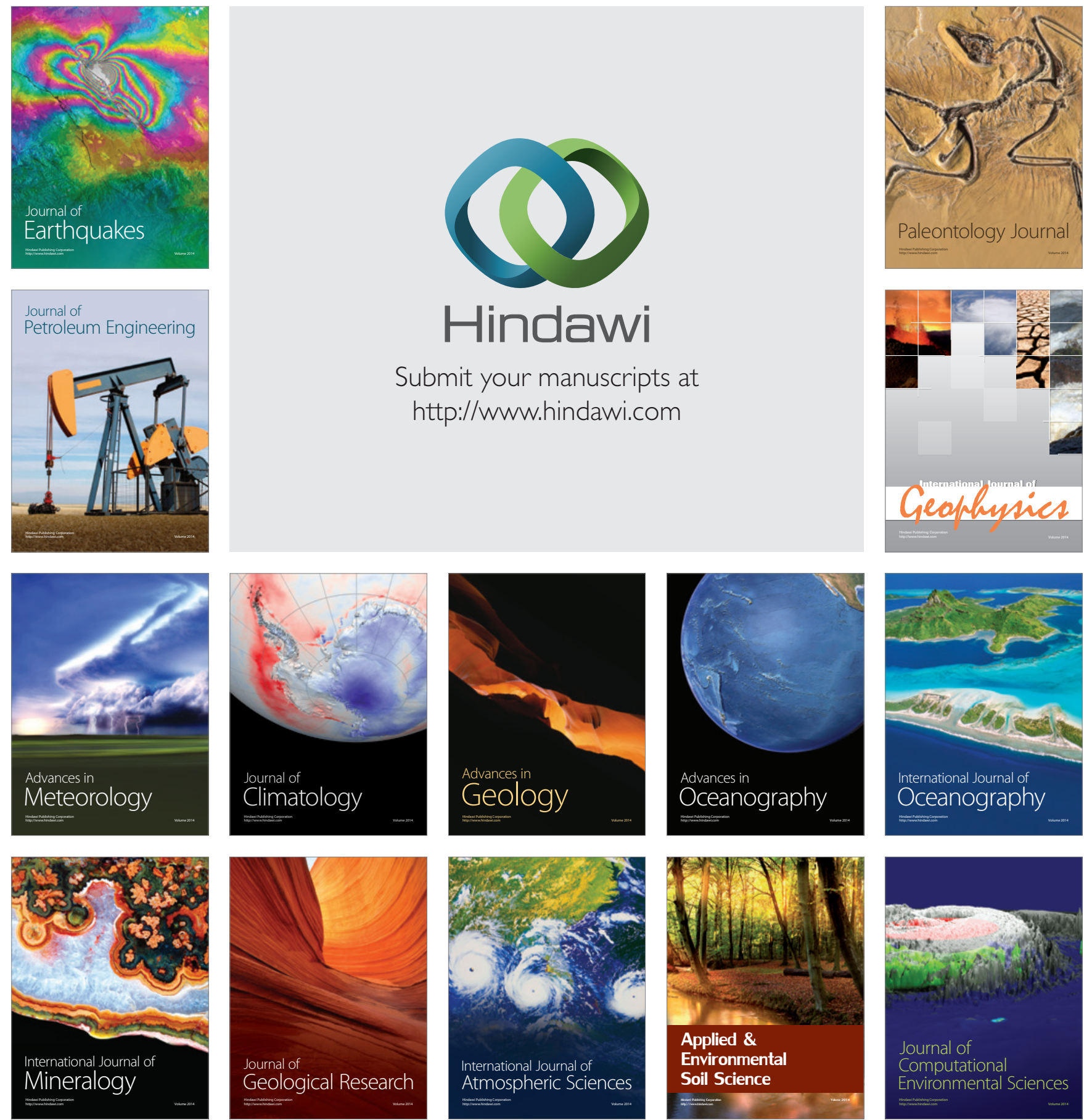